\title{
The Reconstruction of the Disappeared Belief for Modern Civilians
}

\author{
Xuemei Xie ${ }^{1, a}$ \\ Mianyang Normal University Faculty of Marxism, Sichuan, Mianyang, 621000 \\ a email
}

Keywords : Belief,The Lack of Belief ,Traditional Culture, Morality

\begin{abstract}
Belief is one of the fundamental demand of people as well as a method of caring personal emotion. Belief, as a kind of spiritual guide, can save souls and make our society better. From the reason and harm of the absence of belief, we can find that reestablish belief is an important and urgent issue for humanity.
\end{abstract}

\section{Introduction}

Recently, civil belief issue is getting more and more attention, and belief is becoming a common society problem. No matter in academic sector or non-academic sector, a discussion directing at belief issue has started and PhoenixNet and Sohu have taken online survey for Chinese belief issue. In 2010, PhoenixNet has done a special topic about belief and also, taken the online survey 'Chinese Belief Investigation', among which, one question is 'Do you think our modern society is one belief-deficiency society?', and the number of answer 'Yes'is 19039 covering $94.1 \%$, and and 'No'is 1198 covering 5.9\%. (1) In Sohu web, there is also one relevant survey 'Do you think you have belief?' and the answer 'Yes' is 10065 and 'No' is 17491. (2) The proportion of 'No' is 1.7 times of 'Yes', facing which number, and the present belief-deficiency situation from these data, how can we read these signals? How can we face the situation of belief-deficiency? How can we reconstruct belief effectively? These questions are the main content to study and explore in this paper.

Belief is one common concept with long history, and literally speaking, it contains two concepts: believe and dependence, which empasizes congnition; admiration, looking up at, adoration, respect, which emphasizes action. What is relief? As for this question, there are various explanation for that. Here only taking Modern Chinese Dictionary as a reference, the so-called relief refers to the extremely trust and respect to someone or some proposition, isme or religion, and also taking it as model or guideline for yourself action, (3) [1] which is the insistence and honor for certain value, life view or world view. Belief cannot equal to neither faith nor adoration and belief is the hightest value of faith contraposing concept, while adoration contraposes to individual. Belief is not simple, even for one belief, there exising different virgations and although each belief has its own characteristics, they also can mix with each other and coexist in the world. From the classificationm of belief, it can be classified into personal belief and social common belief according to different levels, into political belief, cultural belief, scientific belief, moral belief and religious belief according to different territories, into original belief with the concept of soul as core, religious belief with the concept of god as core and philosophical belief with human itself as core. Belief has the types of science and non-science, advanced and behindhand, generalization and narrow sense and religious belief is the daily said belief with narrow sense. The belief-deficiency in this paper refers to the deficiency of scientific belief, especially to political belief and moral belief not the deficiency of religious belief, which emphasizes the apathy of common belief, the lost of historical direction and the lost of spirit garden.

\section{Harm of Belief-deficiency}

Belief is spiritual pillar for human and the expression of human respect for soul. Human without belief lost their spiritual pillar and spiritual power and then they will lost the enthusiasm to pursue ideal, which will lead to spiritual suffering, confused value, blundering life and vacuous soul, even 
make people live in a rootless life and cannot find a harbour to stay. The result of belief-deficiency can lead to individual happiness, even influenc the development of sociey and country, worsely, become one important potential factor for society instability. Belief is the reflection of human 'Three Contemplations', and although it belongs to spiritual range and ideology field, its great social function cannot be ignored, which can not only maintain or criticize reality but also regulate and control social and human activities. Ideology has relative independentability, and it never has dead calm time, besides, it has active counteractive for social existence. Belief-deficiency is the negative reaction and negative energy of ideology[2].

The harm of belief-deficiency can lead to the lost of China mainstream spirit, even lead to the distortion of mainstream value. Deficiency of spiritual life and spiritual bailment make human become impetuous, anxious to achieve quick success and get instant benefits[3], so more and more people pay more attention to material life and become indulge in a life of pleasure and comfort. Howeve, the pursue for material gain cannot avoid spiritual pain and aeriality and psychological loneliness and lose. Seperation of soul and body, spirit and flesh directly lead to loneliness hard to be drived and sense of belonging find no place to stay. When the deficiency of mainstream spirit become the obvious pain of one century, nomatter how developed our economy is, we cannot say that we are an excellent and civilized nation.

Deficiency of belief can lead to the chaos of social value system, even lead to social shock and seperation. The original belief is abandoned by collectivity, and human thought is in disorder, then the sally port of ideology will be opened soon by western powers and their penetration and destruction willl step into our culture quickly. From the book 1999: Victory Without War [4]wrote by American ex-president Nixon, we can know that when eastern European countries lost their belief totally, then the day come of such westen countries like America peddle their so-called eastern value of human rights, freedom and democracy for which pheaval in eastern Europe has proved. The United States never give up and impossible to give up peaceful evolution to China, in early 1950, operation plan has been made with inner code name Ten Commandments, which has been revised constantly in practice attempting to shake Chinese traditional values of the younger generationfrom from the aspects of ideological, political, economic, cultural, ethnic and religious, which has been fully reflected in United States many years' diplomatic practice. They used substances to seduce and corrupt our youth, and encourage youth to look down upon, contempt and even opposed to the original ideological education publicly, created interest and opportunities on porn open for the youth and encourage casual sex, let our youth forget the shame of superficialness and vain, destroied deliberately our national spirit of bear hardships and stand hard work make our youth become Beat Generation. The action plan of United States is coming to reality step by step and can we still turn a blind eye? Can't it be an alarm for us?

\section{Reason of Relief-deficiency}

In today 21st century, relief-deficien is not only a phenomenon in China, but also a global cultural phenomenon, a worldwide difficult problem, which is the issue that all the countries try to solve. The analysis of the reason of relief-deficiency cannot not only break away from the background with Chinese characteristics, but also from the big pattern of this era, even cannot boil down to a simple personal question.

The missing of countrymen belief stems from the separation of tradition and reality. The phenomenon of China's traditional culture being splitted appeared and thousands of years of cultural accumulation slid to the brink of collapse unfortunately[5]. Nearly hundred years we have criticized fiercely the traditional Chinese culture with the idea of moral supremacy, and in order to catch the step of western world, in order to become 'Civilization', in order to appear 'Fashion', we turned over a new leaf, affirmatively abandoned our Chinese traditional culture and traditional morals with five thousand years' civilization history and introduced western material civilization and spiritual civilization. As a result, the old value system was destroyed but the new value idea system did not yet get perfect, besides, we didn't really absorb the nutrition of world culture and did not learn 
western good moral, finnaly led moral into a vacuum era, further more, the penetrating of non-rationalism trend, the large scale invading of western religions and the embark upon a political venture of heresy, which are all the ideological root causing relief-deficiency.

The lack of faith for countrymen stems from the contradiction between individual and society. In the time of great achievements were made in economic construction, social problems also gradually highlight, and the contradiction between individual and society appears in a continuous stream: the lack of effective checks and balances of power, the lack of effective control of capital, the lack of moral consciousness, growing gap between rich and poor and 'Enemy officer' and 'hatred' phenomenon is escalating. Transition of China is faced with many social problems to be solved: a series of social security problems of housing, health care, education, employment and so on, problem of constant high price level, problem of too rich people doing little good things, food security issues and so on, which lead to intensified social contradictions and social disharmony problem is triggered. Faith should not only influenced by own intellectual culture level, but also by the social environment, life experience, the specific feeling and realistic need, furtherly faith cannot live without the actual real life and the plight and spirit of personal life can easily lead to the 'Suspension' of faith, the 'Aridity' of spirit world and the real life's contrast leads to the lack of faith.

\section{Significance of Relief Reconstruction}

As for the relation of material and consciousness, belief is a kind of consciousness, which is the reaction to the material and has the navigation function for people's life and work as a kind of spiritual power,and it has a great active role[6]. This agency may be positive or negative, which depends on people faith. So building spiritual garden in material times, and restoring faith in modern sociey have great significance. The development of today's society is not only depends on the material basis of spirit, but also depends on spiritual quality. Believing in or do not believing in any religion has great influence on individual, society and country. Because faith is a heartfelt true faith, a voluntary rather than forced or imposed faith with a strong subjective consciousness and emotional color, while once established, the subject will not feel suspicious for the objects and value in their faith easily, and never betrayal and they will persue with perseverance and insistent and in order to realize the transformation of "Ought to" level to "Reality" level, they put their selfless dedication. Having faith makes heart get a place to stay and no matter their faith is correct or not, it will become the spiritual pillar for them:strength resource, operation guide, guiding life, leading life.

In terms of theory of value, belief is a question of value, the most fundamental values[7], the internalization of values, outlook on life and world outlook, the persistent believing on its selection and its own and the lifeblood of people's all behavior, emotion and will. In modern faith diversified society, the selection and evaluation of belief depends on the objective environment and subjective needs, and determined by people specific aim. Different faiths decide people's different value thinking, value orientation and evaluation standard, produce different influences on people's thoughts and actions and determine the direction of people' s life. Right faith can save the soul, lead people to good things and play a function of reconciling and integrating society life, however, wrong belief will lead to confusion, hesitation even falling from grace.

In terms of psychology, belief is the backing of spirit, the direction of effort and it can play a positive role of 'Self-talk'. Faith is the actuator of life orientation and life development. Because of foresight and overlook, although there are many uncertainty factors in reality, there is always unshakable certainty in believer's mentality and emotion, which can stimulate inner powerful driving force to arouse all available resources, such as cognition, emotion and will etc itself or around the surrounding towarding the set goal. Because of unswerving belief, because of oriented sincerity, because of sincere and stedfast belief, whatever difficulties and obstacles encountered you meet on the way of pursuing, you can stubbornly go with the support of faith. The firmer of belief, the stronger of the will: setback cannot ruin you, difficult cannot resist you and interference can't change you. 


\section{Reconstruction of Correct Belief}

The reconstruction of belief not only need to pick up good, traditional, lost and correct belief, but also need to shape, refine, pioneer, innovate, develop, promote new faith based on practice to look for the secular Chinese beliefs for Chinese.

In terms of moral, faith-regain, should return to their homes on the basis of tradition, and express the innate nature of human beings, that is love (Confucian), harmonious (Buddhism) and sincere (Taoism). Chinese believe in love, hate indifference, believe in harmony, oppose conflict, believe in sincere and disgusted with false.

In terms of politics, sticking to faith should persist in the faith of the communist party of China and always don't change, which is to insist on marxism from ideology theory system, and is to fight for communism from the goal of struggle.

In terms of core value system, religion is the soul of the values and faith reconstruction is required to set up the socialist core values of 'prosperous, strong, democratic, civilized and harmonious, freedom, equality, justice, rule of law, patriotic, dedicated, sincere, friendly'. The socialist core values contains a lot of faiths in today's society, nomatter in the level of citizen, society or country, it not only carry on the tradition but also conjunct to the modern; not only embody the value target of national level, but also reflect the social value orientation and the value of the individual level standards and it is both national and social, both extensive and profound and rich generous with the characteristics of compatibility, generality, scientificity and advancement and it is the spirit soul of running a country or people and bringing peace to people and is the social common value pursuit and the belief of Chinese nation.

No matter for the world or country, the nation or personnel, they all need to have belief. When the coordinates of Life is in a mess, it is more necessary to seek and reconstruct lost belief. Belief reconstruction is a difficult course, and it need to find the breakthrough, need the synergetic change of people's concept, feeling and action, need to excavate human nature and need acquired cultivation. Belief reconstruction is the primary task for China, which has a population of 1,300 million, however only $1 \%$ have pay attention to belief issue, so thinking of and discussing belief issue will certainly drive more people to anticipate in it to focus and think. As long as we begin to seek our belief, we will begin to come nearer to our spirit root and as long as we rediscover our root and our belief gets a timely awake, the sleep dragon--China will get overwhelming power to step forward.

\section{References}

[1] http://www.360doc.com/content/10/1230/21/176312_82754362.shtml

[2] http://cul.sohu.com/s2010/faith/\#shushuo

[3] Modern Chinese Dictionary, Commerce and Trade Press, 1987, Beijing

[4] America, Richard Nixon, 1999: Victory Without War [M], Tan Zhaojie etc, Beijing: Chinese People's Public Security University Press, 1988:

Bibliography

[1] Modern Chinese Dictionary [M], Beijing Commerce and Trade Press, 1987

[2] America, Richard Nixon, 1999: Victory Without War [M], Tan Zhaojie etc, Beijing: Chinese People's Public Security University Press, 1988: 